\title{
An Analysis of Harmonic Patterns in the Time Series of the Forex Market
}

\section{Uma Análise de Padrões Harmónicos nas Séries Temporais do Mercado Forex}

DOI: $10.46814 /$ lajdv3n3-052

Recebimento dos originais: 01/05/2021

Aceitação para publicação: 31/06/2021

\author{
Leandro Coelho de Souza \\ Doutor em Computação \\ Instituição de atuação atual: Universidade do Estado da Bahia \\ Endereço completo: Departamento de Ciências Exatas e da Terra, Rua Silveira Martins, 2555, \\ Cabula. CEP: 41.150-000 - Salvador - BA \\ E-mail: leandrocoelho@uneb.br \\ Victor Silveria Ribeiro \\ Bacharelando em Sistemas de Informação \\ Instituição de atuação atual: Universidade do Estado da Bahia \\ Endereço completo: Departamento de Ciências Exatas e da Terra, Rua Silveira Martins, 2555, \\ Cabula. CEP: 41.150-000 - Salvador - BA \\ E-mail: silveiravictor97@gmail.com \\ Diego Frias Suarez \\ Doutor em Modelagem Computacional \\ Instituição de atuação atual: Universidade do Estado da Bahia \\ Endereço completo: Departamento de Ciências Exatas e da Terra, Rua Silveira Martins, 2555, \\ Cabula. CEP: 41.150-000 - Salvador - BA \\ E-mail: diegofrias@uneb.br
}

\begin{abstract}
A challenging environment for research is the behavior of the financial market's time series, especially the stock market and the Forex market, which specializes in currency exchange negotiations. Price fluctuation in both markets have been found to be non-linear, stochastic or temporarily chaotic time series, as well as classified as a complex system. The adaptability and robustness characteristics of complex systems are reflected in the financial market creating waves in asset prices. For this reason, the temporal evolution of prices presents a shape similar to a sequence of waves of different periods and amplitudes. Some traders have noted that two consecutive waves form a pattern similar to M, and that by moving forward a quarter of the first wave period, a pattern similar to $\mathrm{W}$ is obtained. It has been reported from unverified sources that these oscillatory patterns, called harmonics, are often found in stock prices and foreign exchange. Therefore, these standards are currently being used as technical indicators for traders. However, there is no mathematical-statistical systematic to account for the frequency of occurrence of harmonic patterns, just as there is no generalized parametric characterization of harmonic patterns type $\mathrm{M}$ and $\mathrm{W}$ in the reviewed literature consulted. In this article, we address these two cognitive gaps in this important field of knowledge. First, we describe the morphological characteristics of the most popular harmonic patterns, followed by a discrete parameterization that allows to assign an integer to each harmonic pattern. Finally, implementing a
\end{abstract}


simple method, dependent on a parameter, for detecting peaks and values of price waves, we search for harmonic patterns in different currency regions, accounting for the frequency of occurrence of each of them. From the association of popular patterns with the corresponding number in the classification introduced, we conclude that only one of the popular patterns has a probability of occurrence beyond the trivial, at the same time that we identify the most frequent patterns in the studied assets.

Keywords: Forex, Harmonic Patterns, Financial Series.

\section{INTRODUCTION}

The adaptability and robustness (self-regulation) characteristics of complex systems are reflected in the financial market creating waves in asset prices (Ferrari 2005, 73-76) (Wang et al. 2006, 1-2) (Wakefield 2001, 5-12) (Eguíluz, and Zimmermann 2000, 1). Oscillatory patterns, called harmonics, were first reported in 1935 on the American stock market (Gartley 1935, 1-33). The detection of these harmonic patterns has served to guide trading strategies both in the stock market and in the foreign exchange market (Foreign Exchange Market - Forex) (Carney 2010, 109-127) but, to the best of our knowledge, and belief, there are no scientific works that systematize the search for these patterns in the time series of the Forex market, despite being the largest financial market in the world, achieving an amount of daily transactions that exceed 6.6 trillion dollars (Settlement 2019, 3). By comparison, this volume exceeds global stock trading volumes by 25 times. In this market, banks, investment funds, agencies and investors can buy and sell currencies from one country with currencies from another country at the exchange rate at the time of the transaction.

Despite the absence of published works validating this type of pattern in Forex time series, the fact that they are used in practice implies their existence in a regular and satisfactory way, which indicates that these patterns are produced by principles that govern the dynamics of performance in the markets and the psychology that influence traders (Wakefield 2001, 5-12) (Eguíluz, and Zimmermann 2000, 1-2).

An interesting phenomenon that is observed is that the graphic patterns are given little academic names (Trading Strategy Guides, 2021), as for example the so-called "shoulder-head-shoulder" pattern actually refers to a transition from demand (high) to supply (low) and the "butterfly" pattern is formed for two consecutive periods with high and low price swings graphically forming something like the wings of a butterfly linking the high and low peaks and clearly putting the imagination to work. The pattern "Bat" and the "Crab" are also widely cited in the informal publications of the trading communities.

The practical applicability of these patterns is that they point the moment when the current price trend (the last of the pattern) should end and begin a new opposite trend, as well what value the price 
in that new trend can probably reach. That is why they are used to indicate the best time to negotiate and to define profit goals in each negotiation. (Trading Strategy Guides, 2021),

In this work, a scientifically based investigation is carried out on the veracity of the existence of certain harmonic patterns that are repeated with relative frequency in the time series of currency exchange prices. In other words, the assumption that certain patterns develop very frequently and that therefore their identification in real time allows the negotiator to momentarily obtain a predictive capacity capable of supporting a winning negotiation strategy (López 2015, 33-59) was put at issue in this investigation.

Two methods developed to support the research are described, one to detect harmonic patterns and the other to classify the patterns. The method for detecting oscillatory patterns is based on an algorithm for the (late) detection of peaks and valleys. The algorithm uses a threshold, called the (Trend Reversal Distance - DIT), used to determine when a high or low price trend has already ended and was followed by an opposite trend. The method applied to classify the patterns is based on the descriptors used by the authors who will publish on this subject. The harmonic patterns of (Gartley 1935, 205-224) and of (Carney 2010, 41-170), are formed by five consecutive local extremes alternating peaks and valleys, which are joined by four line segments. The usual characterization of these patterns is performed by indicating the relationship between the three (3) price differences (vertical distance between the extremes) between each two consecutive pairs of extremes (joined by a line segment) in the pattern, considering the first pair as a reference for the second, the second for the third and the third for the fourth price pair. In other words, each pattern is represented by three ordered coefficients of relative proportionality of its spans:

$\mathrm{C} 1$ = price difference for leg $2 /$ price difference for leg 1 ,

$\mathrm{C} 2=$ price difference of leg $3 /$ price difference of leg 2 , and

$\mathrm{C} 3=$ price difference for leg $4 /$ price difference for leg 3 .

Another important aspect to be highlighted is that, instead of analyzing the patterns at every five consecutive extremes, it was considered that the patterns are superimposed, that is, sweeping the time series, each time a new extreme appears, the formation of a new pattern that is formed by the new extreme, such as the fifth extreme, and the four previous extremes. Among other reasons, this procedure is a way of eliminating the dependence of the results on the initial conditions of the experiments. The experimental results have shown that the developed method allows organizing the spectrum of patterns into families of infinite sets of morphologically differentiable patterns and accounting for their frequency. 
This paper is organized as follows: Section II presents a brief history of the publications that have dealt with the formation of harmonic patterns in the Forex market and describes their main characteristics. Next, section III is dedicated to describing the methods developed for the detection, identification and classification of harmonic patterns in this work. In section IV the results are presented and discussed, closing in section $\mathrm{V}$ with the conclusions of the work.

\section{HARMONIC PATTERNS IN FOREX}

The pioneering work of (Gartley 1935, 7-10) introduced harmonic patterns in the stock market as a tool for predicting high and low trends. He perceived that joining five consecutive peaks and valleys frequently formed patterns with shapes similar to the letters " $\mathrm{M}$ " and " $\mathrm{W}$ " and that the vertical distances between two successive extremes kept proportions approximately invariant with the vertical distances between the two anterior extremes. In Fig. 1 the scheme that determines the M-shaped Gartley pattern is shown with the average size (height = price difference between the extremes) of each segment given as a proportion (coefficients) of the size of the previous segment.

Figure 1. Schematic representation of Gartley's pattern M.

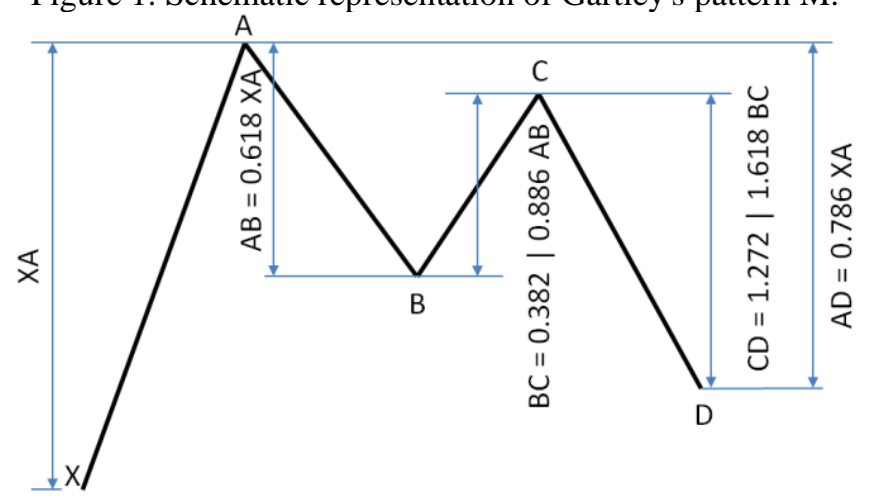

Attention is draw to some important observations:

(i) There are two variants of the Gartley pattern: Gartley-1 when the first coefficient is chosen for the last two sections BC and CD, and Gartley-2 when the second coefficient is chosen;

(ii) Gartley's pattern W is obtained by making a reflection of the surrounding horizontal spill, keeping the coefficients constant. Due to this, only M-type patterns are used here, except for a few exceptions;

(iii)There are so-called anti-patterns that are the same as patterns, but seen from right to left as in a vertical mirror. In this work, due to space limitations, anti-patterns are not treated;

(iv) The horizontal distances between points are not considered, which represent the necessary times to reach a peak in the next valley or vice versa. In this way it can be possible to have patterns of 
very different forms, for example, more extended or more cut, which belong to the same class, but it is not possible to identify it visually;

(v) All patrons include a fourth coefficient that relates the last point D to the first section, XA.

However, the relative position of $\mathrm{D}$ is uniquely determined by the three first coefficients, so the fourth coefficient is unnecessary, as deduced below:

Denoting the coefficients of the left-to-right patterns as $C_{i}, i=1,2,3,4$. Then for a pattern type $M$ we have that the sizes of the sections $\mathrm{AB}, \mathrm{BC}$ and $\mathrm{CD}$ and the relative positions of the extremes $\mathrm{B}, \mathrm{C}$ and $\mathrm{D}$, are given by:

$$
\begin{aligned}
& A B=C_{1} X A, B=A-A B \\
& B C=C_{2} A B, C=B+B C \\
& C D=C_{3} B C, D=C-C D
\end{aligned}
$$

Therefore, the relative position of point $\mathrm{D}$ is given by:

$$
\mathrm{D}=\mathrm{A}-\mathrm{AB}+\mathrm{BC}-\mathrm{CD}
$$

and then the distance between the extremes $\mathrm{A}$ and $\mathrm{D}$ is given by:

$$
\mathrm{AD}=\mathrm{AB}-\mathrm{BC}+\mathrm{CD}
$$

substituting the sizes of the sections and grouping together, we obtain:

$$
\mathrm{AD}=\mathrm{C}_{1}\left(1-\mathrm{C}_{2}\left(1-\mathrm{C}_{3}\right)\right) \mathrm{XA}
$$

so the fourth coefficient is defined as a function of the first three:

$$
\mathrm{C}_{4}=\mathrm{C}_{1}\left(1-\mathrm{C}_{2}\left(1-\mathrm{C}_{3}\right)\right)
$$

For this reason, the definition of a fourth coefficient is not only unnecessary, but it can make the reconstruction of the pattern defined by the first three coefficients unfeasible (if the fourth coefficient given does not coincide, at least approximately, with the result calculated by the formula 5).

\subsection{USAGE OF PATTERNS}

When an M pattern completes (i.e. it's formed), a sustained trend generally begins that is conducive to buying. In the same way, when the $\mathrm{W}$-type pattern is established, a sustained downward trend generally begins, conducive to selling. Statistically, according to the original authors (CARNEY 
SCOTT. 2010), the trend that this pattern follows will have a variation equal to or greater than that of the smallest segment of the established pattern, or that allows to define profit expectations. Figures 2 and 3 show two examples, one with a W pattern and the other with an M pattern, respectively, using real data from the EUR / USD currency pair.

Figure 2. Representation of a Butterfly W pattern in the EURUSD pair that runs from approximately February 28 to March 13,2017 . The end of this pattern signals a downtrend, indicated by the arrow.

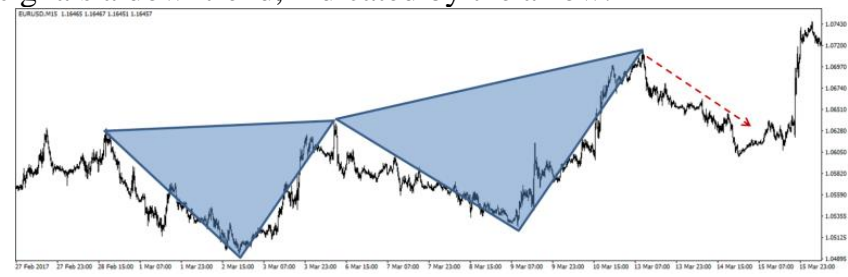

Figure 3. Representation of a bat M pattern in the EURUSD pair that runs approximately between March 2 and March 15, 2017. The end of this pattern signals an upward trend, indicated by the arrow. Note that in this period there is a succession from a butterfly pattern to a bat pattern.

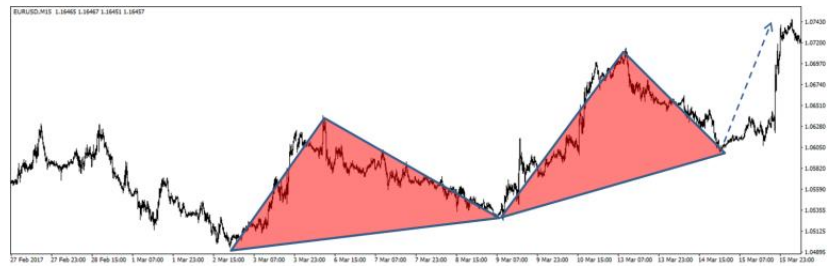

\subsection{CANEY'S PATTERNS}

Following Gartley's line of reasoning, several other authors claim to have discovered harmonic patterns of five different points, in particular, (Carney 2010, 41-149) is the author of four patterns (Butterfly, Bat, Shark and Crab) and Darren Oglesbee (TradingView 2019) is the author of the Cipher pattern.

In order to understand the differences between them, the information (proportionality coefficients) of the two versions of the three most used Carney patterns and the two versions of the Cipher pattern were collected and plotted together with the two versions of the Gartley pattern, in Fig. 4. 


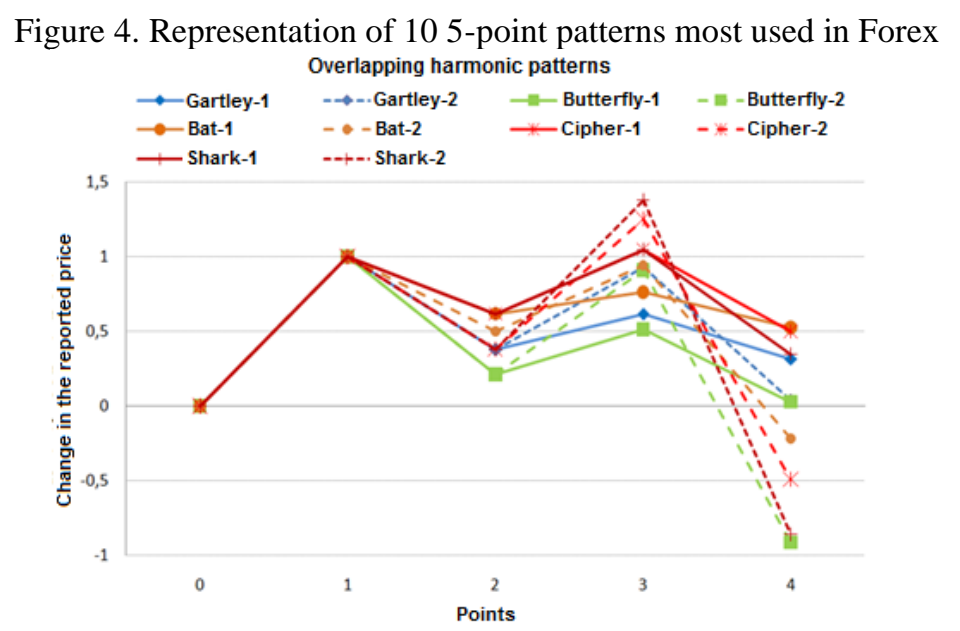

It was observed that the other patterns belong to the same family as the Gartley pattern, since they all have $\mathrm{C}_{3}>1$. However, in general they are more divergent, significantly increasing the size of the sections over time. Diverging patterns are more interesting because they indicate increasing market turmoil, which favors profits and lowers risks. Converging patterns, such as divergent pattern of antipatterns, show a decline in market activity that is not suitable for safe trading.

Finally, it is worth noting that some analysts use patterns with more or less points than Gartley's, varying between three and seven points, but they are not as popular as five points patterns. For this reason, this work focused on the five-point harmonic patterns.

\section{MATERIALS AND METHODS}

\subsection{TIME SERIES USED}

To investigate the frequency of appearance of the harmonic patterns most used in Forex, both in the $\mathrm{M}$ and $\mathrm{W}$ forms, the time series of the EUR/USD currency pair was analyzed in the period from October 10, 2016 to April 21 of 2017, which comprises exactly 27 weeks. To choose the time interval and the currency pair, a study of the available data was carried out to guarantee the temporal continuity of the series. Both the period and the chosen currency pair were those for which the longest time interval was found with continuous data in the database constructed by the research group. This database was obtained by saving the data acquired on a dedicated server since 2016 exclusively to collect Forex data. The server remained connected via the Metatrader 4.0® (MT4) terminal to the data server of a trusted broker through a real account. Connection losses are the causes of the discontinuities of the monitored time series. 


\subsection{DETECTION AND IDENTIFICATION OF HARMONIC PATTERNS}

Pattern detection is performed by identifying the alternating local extremes (peak-valley-peak or valley-peak-valley) in the time series. There are several methods for detecting extremes in real time, such as trend indicators and oscillators (López 2015, 5-10) (Alrefaie, Hamouda, and Ramadan 2013,142) (Sim, Low, Fei-Ching 2010, 1 -2), but all have a delay that can compromise the effectiveness of the trading strategy, and what is even worse is that the delay is not always the same. For this reason, a simple method based on a threshold of opposite price variation was used, called the "trend reversal distance" (DIT) and is given in pips (price variation units).

After the initial trend has been identified, the series is swept, updating the best value reached in the current trend and also the largest price difference in relation to that best value. Every time the difference exceeds the defined DIT, it is considered that the previous trend ended at the time the best value was obtained and that a new (opposite) trend is occurring. The first harmonic pattern is formed when the first 5 extremes are identified and from that moment on, each time a new extreme is identified, the last five extremes are considered a new harmonic pattern.

To evaluate the effect of DIT on the absolute and relative frequency of pattern formation four values of DITs were used: 100, 200, 400 and 600 pips. For the analyzed period, the number of local $\left(e_{j}\right)$ extremes and the number of $n_{j}=e_{j}-4$ patterns were calculated for each DIT $, j=1,2,3,4$. Half of type $\mathrm{M}$ and half of type $\mathrm{W}$ were found. As expected, the number of patterns found inversely depends on the DIT used which reflects the multiscale nature of the complex phenomenon that is the financial market (Miller and Pág. 2007, 9-27). In this context, it was intended to estimate the number of patterns that form weekly in the euro-dollar currency pair according to the DIT, in order to extend the study to other currency pairs in the future.

After a pattern is detected, it is identified. All the harmonic patterns formed are analyzed by comparing the three (3) proportions of their sections with those of the 10 patterns studied (shown in Figure 4). A positive identification implies that within a certain tolerance range the 3 proportions of the pattern found correspond to one of the 10 reference standards. If not, the pattern found is declared unidentified in this phase of the study.

\subsection{CLASSIFICATION OF HARMONIC PATTERNS}

Unlike the identification of patterns by similarity with the characteristics of a set of reference patterns, the classification of patterns has a greater scope, allowing to discover the set of classes described by the harmonic patterns present in the studied Forex time series. 
To create this general classification process, it was necessary to create an encoding. Taking into account that the patterns are characterized by their three coefficients $C_{i},=1,2,3$, it was decided to discretize the interval of variation found for each coefficient $\left[C_{i, \min }, C_{i, \max }\right], i=1,2,3$ in $\mathrm{K}$ classes of the form:

$$
\mathrm{k}_{\mathrm{i}}=1+\left\lfloor\frac{\mathrm{C}_{\mathrm{i}}-\mathrm{C}_{\mathrm{i}, \min }}{\mathrm{C}_{\mathrm{i}, \max }-\mathrm{C}_{\mathrm{i}, \min }}(\mathrm{K}-1)\right\rfloor
$$

where $k_{i}$ is the discrete version of the coefficient $C_{i}$ that varies between 1 and $\mathrm{k}$ being the function $[\cdot]$ the "floor" of the argument that returns the entire part of it. Note that when $C_{i}=C_{i, \min }$ then $\mathrm{k}_{\mathrm{i}}=1$, and when $\mathrm{C}_{\mathrm{i}}=\mathrm{C}_{\mathrm{i} \text { max }}$ then $\mathrm{k}_{\mathrm{i}}=\mathrm{K}$. As each discrete coefficient $\mathrm{k}_{\mathrm{i}}$ can take $\mathrm{k}$ values, then $\mathrm{K}^{3}$ different patterns can be classified, one for each triplet $\left[\mathrm{k}_{1}, \mathrm{k}_{2}, \mathrm{k}_{3}\right]$.

Furthermore, to simplify the classification, instead of considering three values of $\mathrm{k}$, it was decided to introduce a single consecutive classifier given by:

$$
c=k_{3}+K\left(k_{2}-1\right)+K^{2}\left(k_{1}-1\right) \in\left[1, K^{3}\right]
$$

This type of coding groups different families as can be seen in Fig. 4. 1) According to the similarity of the first coefficient: the one that varies less. 2) According to the similarity of the second coefficient: the second that varies less. 3) According to the difference of the third coefficient: the one that varies the most.

The fact of having created a code requires establishing the decoding algorithm. The algorithm consists of three steps. Given the c code of a pattern, it is calculated:

$$
\begin{gathered}
\mathrm{k}_{1}=1+\left\lfloor\frac{\mathrm{c}}{\mathrm{K}^{2}}\right\rfloor \\
\mathrm{k}_{2}=1+\left\lfloor\frac{\mathrm{c}-\mathrm{K}^{2}\left(\mathrm{k}_{1}-1\right)}{\mathrm{K}}\right\rfloor \\
\mathrm{k}_{3}=\mathrm{c}-\mathrm{K}\left(\mathrm{k}_{2}-1\right)-\mathrm{K}^{2}\left(\mathrm{k}_{1}-1\right)
\end{gathered}
$$

\section{RESULTS AND DISCUSSION}

\subsection{DIT EFFECT}

To illustrate the effect of the DIT on the number of harmonic patterns found, Fig. 5 shows the extremes found in the period from October 13 to November 1, 2016, using 200, 400 and 600 pips for DIT configuration. 
Figure 5. Effect of DIT (from top to bottom 200, 400 and 600 pips) on the number of alternating extremes found in the period from 10-13-2016 to 11-1-2016. The solid line joins the ends found during the sweep performed
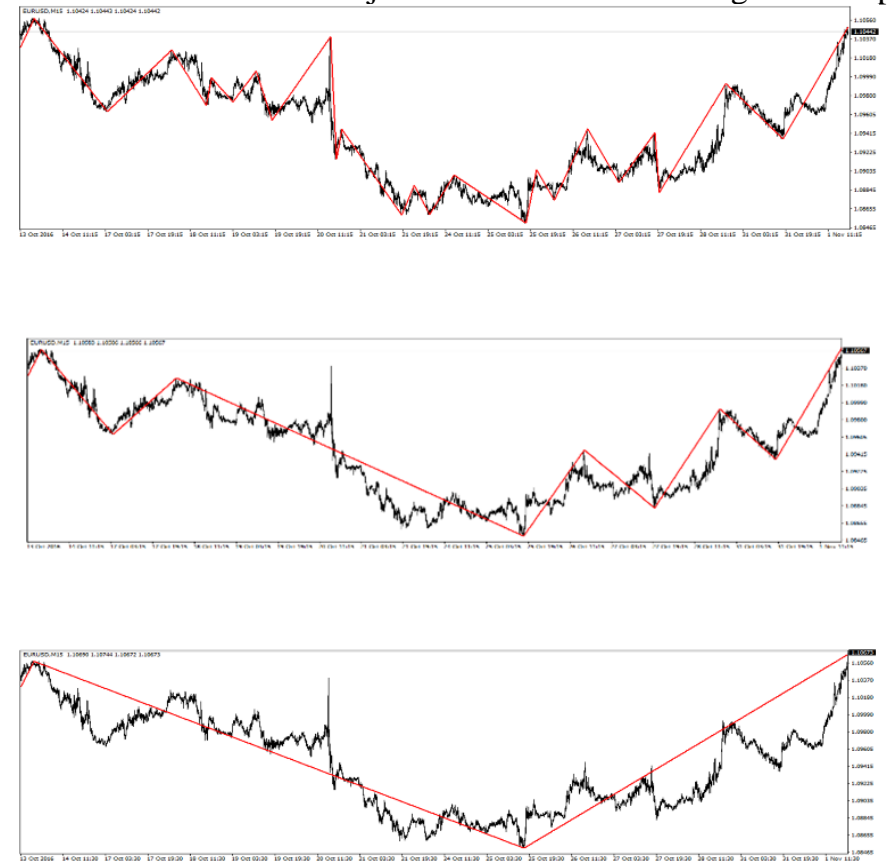

In the period shown in Fig. 5, 25 extremes were found for DIT=200, 9 for DIT=400 and only 3 for DIT=600. In the entire period analyzed, 1051 extremes were found for DIT=100, 4121 for DIT=200, 144 for DIT=400 and 74 for DIT=600, as shown in Fig. 6.

Figure 6. Number of extremes found depending on the inversion distance (DIT), in the EUR/USD currency pair in the period from 10-10-2016 to 04-21-2017.

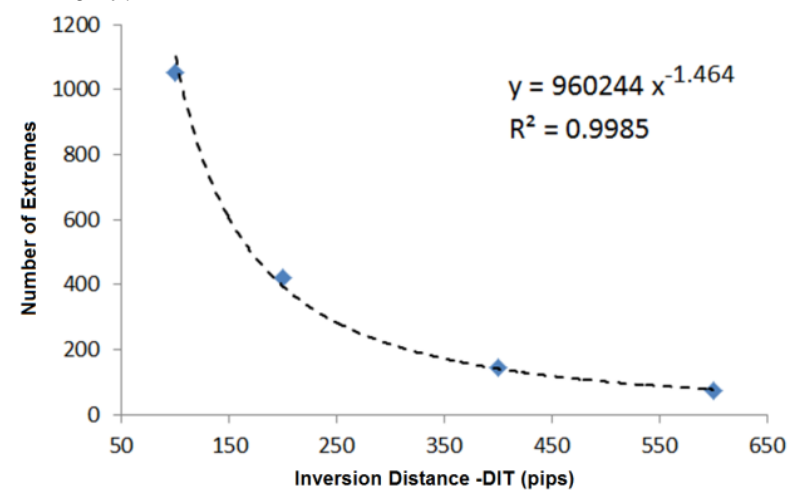

As a result of this study, it was possible to find a power function that allows estimating the number of extremes (or patterns) that can be found per week of operation in the EUR/USD currency pair, depending on the DIT used. 


$$
\mathrm{n}(\mathrm{DIT})=\frac{35564}{\mathrm{DIT}^{1.464}}
$$

This information is extremely relevant for Forex traders since it defines the maximum weekly frequency of possible operations using harmonic patterns, highlighting that it is the maximum frequency, because not all the patterns found will be known patterns such as Gartley's or any other of those studied in this work. Therefore, the second part of the work focused on determining how many of the patterns found were of some known type.

\subsection{GARTLEY'S PATTERN FREQUENCY}

To associate the $\mathrm{M}$ and $\mathrm{W}$ formations found in the series with the Gartley pattern, a tolerance value of $10^{-2}$ was adopted taking into account the precision of 3 decimal places with which the pattern coefficients were published (Gartley 1935, 389-424). However, despite using much greater tolerances, no Gartley pattern was found in the 27 weeks analyzed with any of the 4 DITs considered.

As none of the patterns found was sufficiently similar to the reference pattern used (ie, when the 3 proportionality coefficients of the sections were considered), it was decided to investigate whether at least patterns would be found that had the first two coefficients in the range published by Gartley de according to the adopted tolerance. The question then became the following: How many standards met the first criterion $\left(C_{1}=0.618 \pm 0.01\right)$ and of these how many met the second criterion $\left(C_{1}=0.618 \pm\right.$ 0.01) with several DITs ?

Analyzing the question, considering DIT=100 pips, it was observed that 1,051 harmonic patterns were detected, with only 12 of these patterns (1.14\%) meeting the first criterion and of these, only 3 patterns $(25 \%)$ met the second criterion.

Repeating the study with higher DITs (200, 400 and 600 pips), no pattern was found that met the second condition and, for an inversion distance of 600 pips, no pattern met the first condition. These results confirmed that in the time series of the EUR/USD currency pair, the most traded on Forex, at least during the 27 consecutive weeks considered, the patterns that Gartley found in the stock market in the 1930 s were not really found.

\subsection{CARNEY AND OGLESBEE'S PATTERN FREQUENCY}

The same study was carried out with 8 Scott Carney's harmonic patterns, of which 6 were shown in Fig. 4 and with 2 Oglesbee patterns, but none were found in the EUR/USD time series in the period studied, using the method described, with tolerances of up to 0.1 in the coefficients. 
Table i: list of characteristics of the gartley, carney and oglesbee patterns

\begin{tabular}{|c|c|c|c|c|}
\hline Pattern & $\begin{array}{c}\text { Coefficients } \\
\text { \{c1, c2, c3 }\}\end{array}$ & $\begin{array}{c}\text { Classifiers } \\
\left\{\boldsymbol{k}_{\mathbf{1}}, \boldsymbol{k}_{\mathbf{2}}, \boldsymbol{k}_{\mathbf{3}}\right\}\end{array}$ & Code & $\begin{array}{c}\text { Large } \\
\text { Family }\end{array}$ \\
\hline Gartley-1 & $\{0.618,0.886,1.618\}$ & $\{1,2,3\}$ & 15 & 1 \\
\hline Gartley-2 & $\{0.618,0.382,1.272\}$ & $\{1,1,3\}$ & 3 & 1 \\
\hline $\begin{array}{c}\text { Butterfly- } \\
1\end{array}$ & $\{0.786,0.382,1.618\}$ & $\{2,1,3\}$ & 147 & 2 \\
\hline $\begin{array}{c}\text { Butterfly } \\
-2\end{array}$ & $\{0.786,0.886,2.618\}$ & $\{2,2,5\}$ & 161 & 2 \\
\hline Grab-1 & $\{0.382,0.382,2.240\}$ & $\{1,1,4\}$ & 4 & 1 \\
\hline Grab-2 & $\{0.618,0.886,3.618\}$ & $\{1,2,7\}$ & 19 & 1 \\
\hline Bat-1 & $\{0.382,0.382,1.618\}$ & $\{1,1,3\}$ & 3 & 1 \\
\hline Bat-2 & $\{0.500,0.886,23.618\}$ & $\{1,2,5\}$ & 17 & 1 \\
\hline Shark-1 & $\{0.382,1.130,1.618\}$ & $\{1,2,3\}$ & 15 & 1 \\
\hline Shark -2 & $\{0.618,1.618,2.240\}$ & $\{1,3,4\}$ & 28 & 1 \\
\hline Cipher-1 & $\{0.382,1,130,1,272\}$ & $\{1,2,3\}$ & 15 & 1 \\
\hline Cipher-2 & $\{0.618,1,411,2.000\}$ & $\{1,3,4\}$ & 28 & 1 \\
\hline
\end{tabular}

This result motivated the use of another approach to search for known patterns among the patterns found with the described method. This time, instead of directly comparing the coefficients $\mathrm{C}_{1}, \mathrm{C}_{2}, \mathrm{C}_{3}$ of the pattern found with the reference values of the searched patterns, the discrete coefficients $\mathrm{k}_{1}, \mathrm{k}_{2}, \mathrm{k}_{3}$ and the classifier $\mathrm{c}$ of each of the 10 searched patterns were calculated as shown in Table I, and subsequently calculated the frequency of each large family $\left(\mathrm{k}_{1}\right)$ and each family $\left(\mathrm{k}_{2}\right)$ to which the researched patterns belong. The results obtained in this way will be discussed in the next section.

Summarizing, the data in Table I show that the 12 harmonic patterns studied are reduced to 8 different patterns with codes: 3 (Gartley-2 and Bat-1), 4 (Crab-1), 15 (Gartley-1, Shark- 1 and Cipher1), 17 (Bat-2), 19 (Crab-2), 28 (Shark-2 and Cipher-2), 147 (Butterfly-1) and 161 (Butterfly-2).

\subsection{MORE FREQUENCY HARMONIC PATTERNS}

To evaluate the new harmonic pattern classification method, a DIT=200 pips was chosen with which 418 patterns were detected and $\mathrm{K}=12$ was established to differentiate 1,728 patterns, divided into 12 large families and 144 families. Figure 7 shows the frequency histogram obtained with these parameters in the period considered. Each grouping corresponds to a large family. Of the 12 large families, 11 were identified. The large family for $\mathrm{k}_{1}=11$ was not detected. The largest large family is that of $\mathrm{k}_{1}=2$ followed by the families of $\mathrm{k}_{1}=1$ and $\mathrm{k}_{1}=3$. Large families with $\mathrm{k}_{1}>5$ are not numerous. 
Figure 7. Frequency histogram of the patterns found with the inversion distance of 200 pips and $\mathrm{K}=12$.

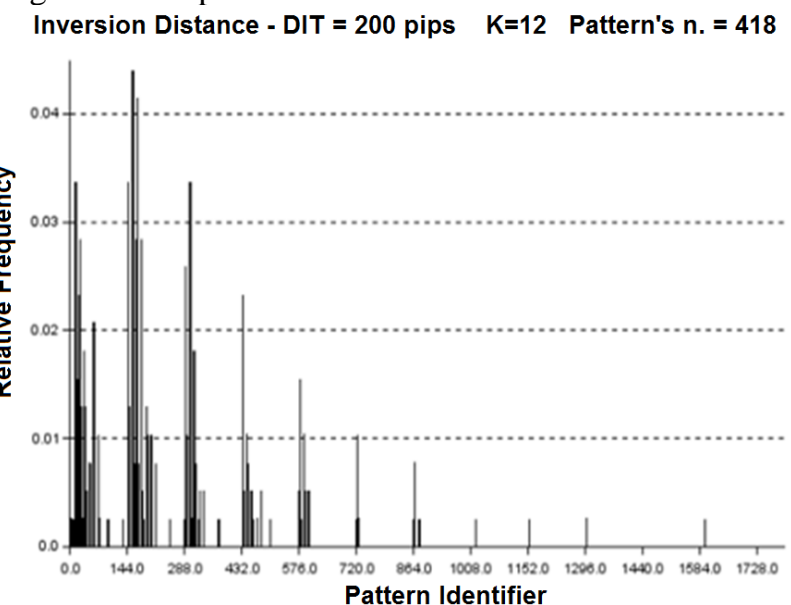

As can be seen in Table I, most of the patterns searched belong to large family 1, except for the two butterfly patterns that belong to large family 2 . This coincides with the opinion of the majority of technical analysis specialists who have confirmed, in practice, that the Butterfly patterns are the most frequent.

In the 418 patterns found, there are 113 different patterns, of which 39 patterns appeared only once (34.5\%). $36.1 \%$ of the remaining 74 patterns appeared more than 9 times and $70.5 \%$ more than 4 times.

Of the 418 patterns found in the time series, 11 were classified with code 15 , to which the patterns belong: Gartley-1, Shark-1 and Cipher-1. This represents only $2.6 \%$ of the patterns. The Gartley-2 pattern, which shares code 3 with the Bat-1 pattern, appeared only once $(\sim 0.24 \%)$. In short, Gartley patterns are less than $3 \%$ of the harmonic patterns found with DIT=200 pips and $\mathrm{K}=12$.

In Fig. 8 we show the frequency of all the patterns found in the first large family indicating the position of the two Gartley patterns. Only 9 of the 12 families in this large family are present, the families for $\mathrm{k}_{2}=2,3,4$ being the most numerous from highest to lowest. The most frequent pattern in family 2 is the neighbor of the Gartley-1 pattern that has code 14 . The Gartley-1 pattern is the second most numerous in its family, but Gartley-2 is not significant. 
Figure 8. Frequency histogram of the patterns of the first family found with an inversion distance of 200 pips and $\mathrm{K}=12$.

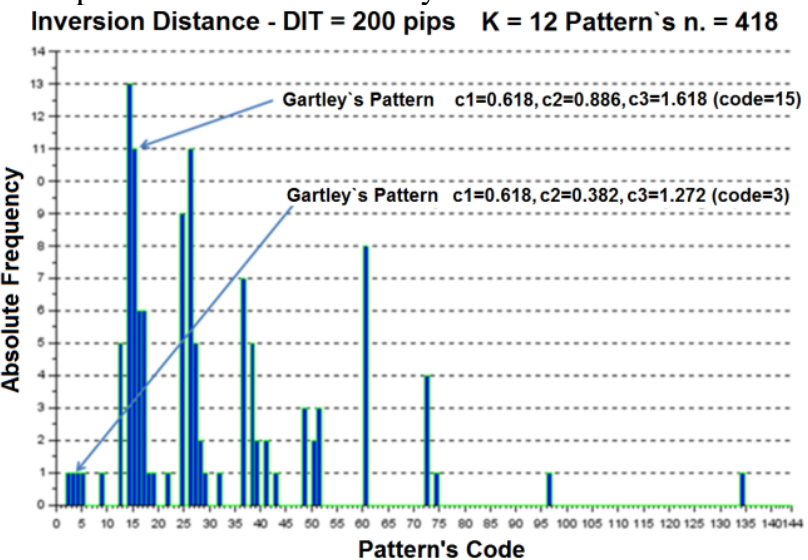

The frequencies of the Gartley and Carney patterns are shown in Table II.

Table ii: frequency of the gartley, carney and oglesbee harmonic patterns by order of appearance frequency

\begin{tabular}{|c|c|c|c|c|c|c|c|}
\hline Pattern & Code & Frequency & $\%$ & Pattern & Code & Frequency & $\%$ \\
\hline Shark-1 & 15 & 11 & 2.6 & Butterfly1 & 147 & 6 & 1.4 \\
\hline Shark -2 & 28 & 2 & 0.5 & Butterfly2 & 161 & 3 & 0.7 \\
\hline Cipher-1 & 15 & 11 & 2.6 & Bat-1 & 3 & 1 & 0.25 \\
\hline Cipher -2 & 28 & 2 & 0.5 & Bat-2 & 17 & 6 & 1.4 \\
\hline Gartley1 & 15 & 11 & 2.6 & Grab-1 & 4 & 1 & 0.25 \\
\hline Gartley2 & 3 & 1 & 0.25 & Grab-2 & 19 & 1 & 0.25 \\
\hline \multicolumn{2}{|c|}{ TOTAL } & 38 & 9.1 & \multicolumn{7}{c|}{ TOTAL } & 18 & 4.2 \\
\hline
\end{tabular}

The patterns searched are only 56 out of a total of 418 patterns found, which represents $13.3 \%$. The only patterns that belong to the second family, which is the one with the highest frequency, are the Butterfly patterns, which appear 9 out of 56 times (16\%).

Of the 418 patterns found, 39 appeared only once, 24 appeared 2 times, 12 appeared 3 times, and 38 appeared more than 3 times. In table III we show the code and the number of occurrences of the 10 most frequent patterns. These patterns represent approximately $33.7 \%$ of the 379 patterns, of the total of 418 patterns, that appeared more than once and will be studied more deeply in future work.

Table iii: code, large family and frequency of the 10 most frequent patterns (from greatest to lowest).

\begin{tabular}{|c|c|c|c|c|c|}
\hline Code & $\begin{array}{c}\text { Large } \\
\text { Family }\end{array}$ & Frequency & Code & $\begin{array}{c}\text { Large } \\
\text { Family }\end{array}$ & Frequency \\
\hline 158 & 2 & 17 & 159 & 2 & 12 \\
\hline 170 & 2 & 16 & 15 & 1 & 11 \\
\hline 14 & 1 & 13 & 26 & 1 & 11 \\
\hline 146 & 2 & 13 & 169 & 2 & 11 \\
\hline 302 & 3 & 13 & 181 & 2 & 11 \\
\hline
\end{tabular}

To finalize this phase of the study, we analyze the variability of the patterns that have the same code. 
The sum of the frequencies of the 10 most frequent patterns totalize 128, which represents $30.6 \%$ of the total of patterns found. Of the 10 most frequent patterns, $60 \%$ are from the large family 2 and $30 \%$ from the big family 1 . Only 1 of the most frequent patterns belong to the big family 3 .

The discretization of the coefficients in the K classes causes the same code to be attributed to similar patterns. Proximity is determined by class size, given by:

$$
\Delta \mathrm{C}_{\mathrm{i}}=\left(\mathrm{C}_{\mathrm{i}, \max }-\mathrm{C}_{\mathrm{i}, \min }\right) /(\mathrm{K}-1)
$$

denoting by $\mathrm{C}_{\mathrm{i}, \mathrm{k}}$ the central value of the coefficient $\mathrm{i}$ in the class $\mathrm{k}_{\mathrm{i}}$, given by:

$$
\mathrm{C}_{\mathrm{i}, \mathrm{k}}=\mathrm{C}_{\mathrm{i}, \min }+\left(\mathrm{k}_{\mathrm{i}}-\frac{1}{2}\right) \Delta \mathrm{C}_{\mathrm{i}}
$$

for $\mathrm{k}_{\mathrm{i}}=1,2, \ldots \mathrm{K}$, all the patterns whose coefficient $\mathrm{C}_{\mathrm{i}}$ belongs to the interval $\left[\mathrm{C}_{\mathrm{i}, \mathrm{k}}-\frac{\Delta \mathrm{C}_{\mathrm{i}}}{2}, \mathrm{C}_{\mathrm{i}, \mathrm{k}}+\right.$ $\left.\frac{\Delta C_{i}}{2}\right]$, in which $\frac{\Delta C_{i}}{2}$ is the tolerance allowed to the coefficient $C_{i}$ when this procedure is used. In other words, all the patterns whose coefficients $C_{i}=C_{i, k} \pm \frac{\Delta C_{i}}{2}$ will have the same class $k_{i}$ assigned to their ith coefficient.

Due to this, a pattern does not represent a polygonal in the price versus time chart, but rather a region as shown in Fig. 9. In the left side of the figure, pattern 158 is shown, which is the most frequent in the period analyzed and in the right side pattern 15 is shown, which is the most frequent of the harmonic patterns studied.

Figure 9. Region defined by code patterns 158 (most frequent) and 15 to which the Gartley-1, Shark-1 and Cifher- 1 patterns belong.
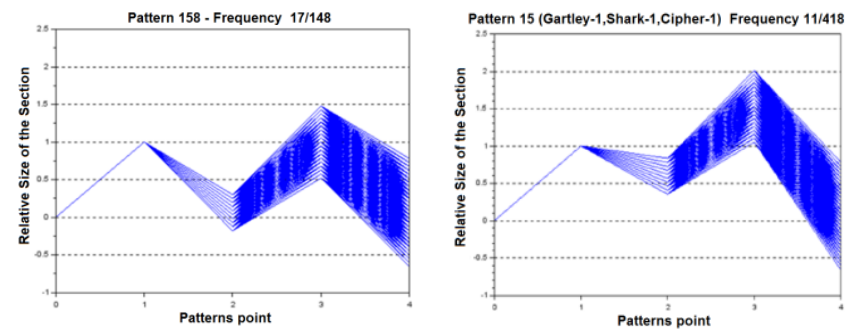

It is worth noting that pattern 158 is almost $55 \%$ more frequent than the most frequent patterns used in technical analysis, so it deserves to be studied for its application in automated trading strategies. In particular, it will be important to determine the statistical distribution of the height of the high trend that comes after the formation of this pattern, to calculate the probability of success based on the 
defined profit goal. It will also be convenient to analyze if there is any correlation between the height of the high trend that follows this pattern and the height of the last downtrend of the pattern 158 .

\section{CONCLUSIONS}

The occurrence of harmonic patterns in the Forex market is a matter not yet clarified by the scientific community. For this reason, the time series of the Forex market were analyzed, looking for the main harmonic patterns described in the literature, but none of these patterns was found. In view of this situation, a new method of classifying harmonic patterns in financial series was developed.

The experimental results have shown that the developed method allows organizing the spectrum of patterns into families of infinite sets of morphologically differentiable patterns.

A power function was also proposed that allows to calculate exactly the number of patterns that can be found per trading week in the EUR/USD currency pair. This information is extremely relevant for Forex traders as it defines the maximum weekly trading frequency possible using harmonic patterns. 


\section{REFERENCES}

Alrefaie Mohamed, Hamouda Alaa-Aldine, And Ramadan Rabie. 2013. "A Smart Agent To Trade And Predict Foreign Exchange Market." 2013 Ieee Symposium On Computational Intelligence For Engineering Solutions (Cies), Singapore: 141-148. Https://Doi.Org/10.1109/Cies.2013.6611741

Bank For International Settlement. 2019. "Triennial Central Bank Survey: Foreign Exchange Turnover In April 2019", Monetary And Economic Department, September 16, 2019: 1-21. Https://Www.Bis.Org/Statistics/Rpfx19_Fx.Pdf

Carney Scott. 2010. Harmonic Trading: Volume One Profiting From The Natural Order Of The Financial Markets. New Jersey: Pearson Education.

Eguíluz Victor, And Zimmermann Martin. 2000. "Transmission Of Information And Herd Behavior: An Application To Finantial Markets." Physical Review Letters 85, 5659-5662. Https://Doi.Org/10.1103/Physrevlett.85.5659.

Gartley Harold. 1935. Profits In The Stock Market. Pomeroy, Washington: Lambert-Gann Publishing.

López Alejandro. 2015. "Modelos Predictivos Para El Mercado Forex." Msc Diss., Facultad De Matemáticas, Universidad De Murcia.

Miller John, And Page Scott. 2007. Complex Adaptive Systems: An Introduction To Computational Models Of Social Life. Princeton, New Jersey: Princeton University Press.

Rojo Ferrari, S. 2005. "La Complejidad: Un Nuevo Enfoque De La Economía Financiera", En Contaduría Y Administración, 73-99.

Sim Kwan, Low C. , And Fei-Ching Kuo. 2010. "Detecting Faults In Technical Indicator Computations For Financial Market Analysis," The 2nd International Conference On Information Science And Engineering, Hangzhou: 2749-2754. Https://Doi.Org/10.1109/Icise.2010.5689221.

Tradingstrategyguides. 2021. "Butterfly Harmonic Pattern Trading Strategy ". April 28,2021. Https://Tradingstrategyguides.Com/Butterfly-Harmonic-Pattern-Trading-Strategy/

Tradingview. 2019. "Predictions And Analysis: Cypher". Accessed May 1, 2019. Https://Www.Tradingview.Com/Ideas/Cypherpattern/

Wakefield Julie. 2001. "Complexity's Business Model. Part Physics, Part Poetry--The Fledgling UnDiscipline Finds Commercial Opportunity.” Scientific American January. 23-24.

Wang Yougui, Wu Jinshan, And Di Zengru. 2006. "Physics Of Econophysics.” Working Paper Of Bejing Normal University, No. 1025: 1-23. 